\title{
Planned Teaching Program on Knowledge and Practice Regarding Legal and Ethical Issues in Care of Children
}

\author{
Priya darsini A. ${ }^{1^{*}} \&$ Sowmiya K. ${ }^{2}$ \\ ${ }^{1,2}$ Department of Child Health Nursing, Saveetha College of Nursing, SIMATS, Thandalam, Chennai, Tamilnadu, India. \\ Corresponding Author Email: apriyadarsini1987@ gmail.com ${ }^{1 *}$
}

DOI: http://doi.org/10.38177/ajast.2021.5216

Copyright: (02021 Priya darsini A. \& Sowmiya K. This is an open access article distributed under the terms of the Creative Commons Attribution License, which permits unrestricted use, distribution, and reproduction in any medium, provided the original author and source are credited.

Children are perceived as the happiness of the family. They satisfy parent's emotional, psychological, social and spiritual needs. Children prolong the parent's existence into future This expansion has focused new concerns among nurses, especially pediatric nurses to have heightened awareness of legal and ethical issues. The present study aims to assess the knowledge and practice regarding legal and ethical issues in care of children among nurses working in pediatric ward. A quantitative pre Experimental one group Pre test posttest research design among 60 samples of pediatric nurses using Non-probability convenient sampling technique using select samples Semi-structured interview was used to collect demographic data and it seeks information about Knowledge on Legal and Ethical aspects of Pediatric Nursing. The study result shows that in the pretest, 55 (91.67\%) had inadequate knowledge and $5(8.33 \%)$ had moderately adequate knowledge.

Whereas in the post test, $56(93.33 \%)$ had adequate knowledge and $4(6.67 \%)$ had moderately adequate knowledge regarding legal and ethical issue in care of children among nurses. And regarding practice in pretest, $52(86.67 \%)$ had inadequate practice and $8(13.33 \%)$ had moderately adequate practice. Whereas in the post test, $51(85 \%)$ had adequate practice and $9(15 \%)$ had moderately adequate practice regarding legal and ethical issues in care of children among nurses.

And found to be statistically highly significant at $p<0.001$ level. This clearly infers that planned teaching programme regarding legal and ethica issues in care of children administered to nurses was found to be effective and significant improvement was observed in the pre test and post test leve of knowledge and practice regarding legal and ethical issues in care of children administered to nurses

Keywords: Pediatric nurses, Knowledge regarding legal and ethical issues, Practice regarding legal and ethical issues.

\section{Introduction}

Children are perceived as the happiness of the family. They satisfy parent's emotional, psychological, social and spiritual needs. Children prolong the parent's existence into future ${ }^{1}$. Ethics are standards which health care professionals referred for the determination of right action. Nursing ethics is a system of principles governing the conduct of a nurse and is a branch of applied ethics that concerns itself with activities in the field of nursing.

The dictionary defines nursing ethics as the values and principles governing nursing practice, conduct and relationships ${ }^{2}$. Ethical considerations are vital in any area dealing with human beings because they respect values, rights and relationships. Nurses are obligated to provide ethical and legal client care that demonstrates respect for others. Ethics is the science that deals with the rightness or wrongness of action ${ }^{3}$.

Nurses should be sensitive to the ethical challenges and do their best to fulfill their moral duties. It also emphasizes the importance of informed consent and address main ethical issues in everyday practice such as respect to privacy and confidentiality of patients, clients, relationship with colleagues, efficient performance of the professional duties and protection of participants in research. The nurse's education, license and standard provide the framework by which nurses are expected to practice.

The legal implications of nursing practice are related to licensure, state and federal laws, scope of practice and a public expectation that nurses practice at a high professional standard. The nurse's education, license and standard 
provide the framework by which nurses are expected to practice. When a nurse's practice falls below acceptable standards of care and competence, this exposes the nurse to litigation. Both litigation and professional license review can result in reprimand of a nurse's license or loss of a license ${ }^{4}$. Nurses face legal issues daily. Those issues may be in connection to negligence, administering medication and advocating for the patient. If these duties and regulations are not followed, the nurse is at risk of losing his/her license and facing a malpractice suit. So Nursing professionals need to improve and update their knowledge in regards to legal and ethical principles and incorporate the knowledge in decision making in daily practice ${ }^{5}$.

The challenges faced by the nurses and to prefer strategies for decision making. They observed that Maternal and Child Health Nurses are usually faced with the problems of decision making in dealing with ethical issues in practice. It is either they make a wrong decision, delay decision making or fall in a state of dilemma when dealing with such issues.

This review revealed that ethical issues remain a challenge. Maternal and Child Health Nurses need to be aware of the steps in decision making, and be conversant with their professional ethics ${ }^{6}$.

American journal of disease of children conducted a survey to identify strengths and weaknesses in Medico Legal knowledge among 63 Pediatric faculty and residents in Melbourne. The results showed that residents (67\%) were more likely to had Medico Legal coursework than faculty (26\%). Faculty and residents had similar scores (80.6\% and $83.7 \%$, respectively).The study concluded that faculty and residents have areas of deficient knowledge for Medico Legal issues, therefore, formal medico legal education is recommended ${ }^{7}$.

Journal on the malpractice litigation crisis, it affects all clinical health care professional development in India. Providers were sued by patients for professional's negligence, injury from defective products, breach of contract or intentional acts and omissions. It focused on both professional products and service delivery. Prosthetics and Orthotics are particularly vulnerable to professional negligence and product liability claims. While it is a vital to maintain an altruistic focus in care delivery, clinicians and managers also must practice effective malpractice risk management ${ }^{8}$. Today's health care delivery system is more dynamic and role of nurses has expanded rapidly, because nurses are confronted every day with a situation in which a difficult decision must be made based on the determination of right and wrong which expects specialization, autonomy and accountability from both ethical and legal perspective. This expansion has focused new concerns among nurses, especially pediatric nurses to have heightened awareness of legal and ethical issues ${ }^{9}$.

To avoid legal issues, a nurse should follow the standards of care, to provide competent care, communicate with other health care workers and develop a good therapeutic caring relationship. Documentation should be accurate, complete, factual, legible and have current knowledge of nursing practice. Nurses perform duties based on physician's instructions and use their own judgement as necessary. Ethics in nursing includes fair and equable treatment of all patients regardless of age, gender, caste, creed, religion, culture, ethnicity, citizenship, disability socio-economic and political status, personal attributes, or any other grounds ${ }^{10}$. A recent study conducted to assess the knowledge and practice regarding legal and ethical issues in care of children among nurses working in pediatric ward. The recent study indicates the post test mean score of knowledge was 21.83 with standard deviation 
Asian Journal of Applied Science and Technology (AJAST)

Volume 5, Issue 2, Pages 117-123, April-June 2021

1.97 and the post test mean score of practice was 12.73 with standard deviation 1.35. The calculated Karl Pearson's Correlation value ' $r$ ' $=0.856$ shows high positive correlation between post test knowledge and practice scores which was found to be statistically highly significant at $\mathrm{p}<0.001$ level.

The purpose of the study was:

(1) To assess the pretest and post test level of knowledge and practice regarding legal and ethical issues in care of children among nurses working in Pediatric wards.

(2) To evaluate the effectiveness of planned teaching programme on legal and ethical issues in care of children among nurses working in Pediatric wards.

(3) To establish a relationship between post test knowledge and practice regarding legal and ethical issues in care of children among nurses working in Pediatric wards.

(4) To associate the post test level of knowledge and practice regarding legal and ethical issues in care of children among nurses working in Pediatric wards with their selected demographic variables.

\section{Methods and Materials}

An quantitative research approach with pre Experimental One group pre-test post-test research design was used to conduct the study in Chennai. 60 samples were selected by using Non-probability convenient sampling technique. The criteria for sample selection were the registered nurses those who are working in Saveetha Medical College and Hospital, Chennai and who are willing to participate. The exclusion criteria for the samples were who are working in operation theatre and outpatient department and who are in night shift. The data collection was done with prior permission from the Principal of Saveetha College of Nursing and ethical clearance was obtained from the institution (SIMATS). The investigator induced and explained the purpose of the study to samples and the written informed consent. A questionnaire was divided into two sections which includes the semi structured questionnaire seeks information regarding knowledge on Legal and Ethical aspects of Pediatric Nursing. It consists of 25 items as follows:

Part - 1: Legal aspects in Pediatric Nursing - 15 items Part - 2: Ethical aspects in Pediatric Nursing - 10 items. In the semi structured knowledge questionnaire, each correct answer was given a score of ' 1 ' and the wrong answer was given a score of " 0 ". Data collection period was for 1 week to collect data from the registered nurses i.e., Nurses working at Saveetha Medical College and Hospital, Chennai.

\section{Results and Discussions}

\section{SECTION A: Description of the Demographic Variables of Nurses}

The present study shows that most of the nurses 45 (75\%) were aged below 30 years, 60 (100\%) females, 47 (78.3\%) had done B.Sc. Nursing, 30 (50\%) were working in Pediatric medical and surgical ward \& postnatal ward, $30(50 \%)$ had 6 months - 1 year of experience, $45(75 \%)$ had below 2 years of experience, $40(66.7 \%)$ had no legal and ethical issues, 60 (100\%) were aware of malpractice and 47 (78.3\%) had not attended any training program on legal and ethical issues in care of children. 


\section{SECTION B: Assessment of Level of Knowledge and Practice Regarding Legal and Ethical Issues in Care of}

\section{Children Among Nurses}

Table 1. Frequency and percentage distribution of level of knowledge regarding legal and ethical issues in care of children among nurses $\quad \mathrm{N}=60$

\begin{tabular}{|c|cccccc|}
\hline \multirow{2}{*}{ Knowledge } & \multicolumn{2}{|c}{$\begin{array}{c}\text { Inadequate Knowledge } \\
(\leq 50 \%)\end{array}$} & $\begin{array}{c}\text { Moderately Adequate } \\
\text { Knowledge }(51-75 \%)\end{array}$ & \multicolumn{2}{c|}{$\begin{array}{c}\text { Adequate Knowledge } \\
(>75 \%)\end{array}$} \\
\cline { 2 - 6 } & No. & $\%$ & No. & $\%$ & No. & $\%$ \\
\hline Pretest & 55 & 91.67 & 5 & 8.33 & 0 & 0 \\
\hline Post Test & 0 & 0 & 4 & 6.67 & 56 & 93.33 \\
\hline
\end{tabular}

The above table 1 shows that in the pretest, $55(91.67 \%)$ had inadequate knowledge and $5(8.33 \%)$ had moderately adequate knowledge. Whereas in the post test, 56 (93.33\%) had adequate knowledge and $4(6.67 \%)$ had moderately adequate knowledge regarding legal and ethical issues in care of children among nurses.

Table 2. Frequency and percentage distribution of level of practice regarding legal and ethical issues in care of children among nurses $\quad \mathrm{N}=60$

\begin{tabular}{|c|cccccc|}
\hline \multirow{2}{*}{ Practice } & \multicolumn{2}{|c}{$\begin{array}{c}\text { Inadequate Practice } \\
(\leq 50 \%)\end{array}$} & $\begin{array}{c}\text { Moderately Adequate } \\
\text { Practice }(51-75 \%)\end{array}$ & \multicolumn{2}{c|}{$\begin{array}{c}\text { Adequate Practice } \\
\end{array}$} & \multicolumn{2}{c}{$\begin{array}{c}(>75 \%) \\
\end{array}$} & No. & $\%$ & No. & $\%$ & No. & $\%$ \\
\hline Pretest & 52 & 86.67 & 8 & 13.33 & 0 & 0 \\
\hline Post Test & 0 & 0 & 9 & 15.0 & 51 & 85.0 \\
\hline
\end{tabular}

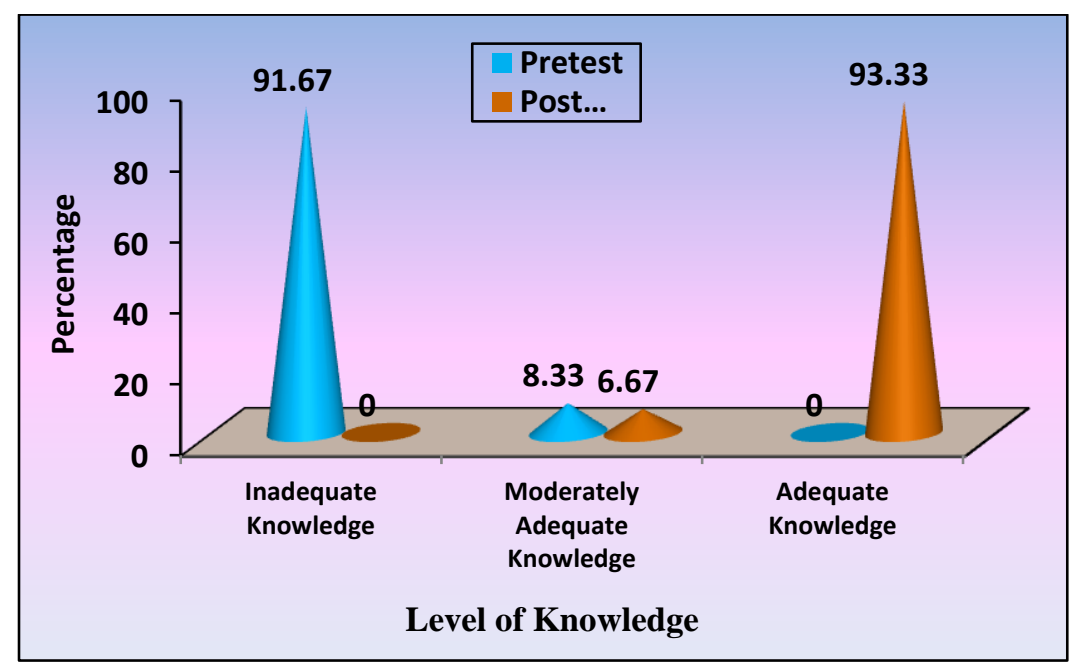

Fig.1. Percentage distribution of level of knowledge regarding legal/ethical issues in care of children among nurses 
The above table 2 shows that in the pretest, $52(86.67 \%)$ had inadequate practice and $8(13.33 \%)$ had moderately adequate practice. Whereas in the post test, $51(85 \%)$ had adequate practice and $9(15 \%)$ had moderately adequate practice regarding legal and ethical issues in care of children among nurses.

\section{SECTION C: Effectiveness of Planned Teaching Programme on Knowledge and Practice Regarding Legal and} Ethical Issues in Care of Children among Nurses

Table 3. Effectiveness of Planned Teaching Programme on Knowledge and Practice Regarding Legal and Ethical Issues in Care of Children among Nurses $\mathrm{N}=60$

\begin{tabular}{|c|c|c|c|}
\hline Knowledge & Mean & S.D & Paired 't' test Value \\
\hline Pretest & 9.21 & 2.42 & $\mathrm{t}=33.365$ \\
Post Test & 21.83 & 1.96 & $\mathrm{p}=0.0001$ \\
& & $\mathrm{~S} * * *$ \\
\hline
\end{tabular}

The table 3 depicts that the pretest mean score of knowledge was 9.21 with standard deviation 2.42 and the post test mean score of knowledge was 21.83 with standard deviation 1.96. The calculated paired ' $t$ ' test value of $t=33.365$ was found to be statistically highly significant at $\mathrm{p}<0.001$ level.

This clearly infers that planned teaching programme regarding legal and ethical issues in care of children administered to nurses was found to be effective and significant improvement was observed in the post test level of knowledge regarding legal and ethical issues in care of children administered to nurses.

Table 4: Comparison of pretest and post test level of practice regarding legal and ethical issues in care of children among nurses $\quad \mathrm{N}=60$

\begin{tabular}{|c|c|c|c|}
\hline Practice & Mean & S.D & Paired 't' test Value \\
\hline Pretest & 5.22 & 1.83 & $\mathrm{t}=26.128$ \\
\hline Post Test & 12.73 & 1.35 & $\mathrm{p}=0.0001$ \\
& & $\mathrm{~S} * * *$ \\
\hline
\end{tabular}

The table 4 depicts that the pretest mean score of practice was 5.22 with standard deviation 1.83 and the posttest mean score of practice was 12.73 with standard deviation 1.35 .

The calculated paired ' $\mathrm{t}$ ' test value of $\mathrm{t}=26.128$ was found to be statistically highly significant at $\mathrm{p}<0.001$ level.

This clearly infers that planned teaching programme regarding legal and ethical issues in care of children administered to nurses was found to be effective and significant improvement was observed in the post test level of practice regarding legal and ethical issues in care of children administered to nurses. 
Asian Journal of Applied Science and Technology (AJAST)

Volume 5, Issue 2, Pages 117-123, April-June 2021

SECTION D: Relationship between Knowledge and Practice Regarding Legal and Ethical issues in care of children among Nurses

Correlation between post-test knowledge and practice scores regarding legal and ethical issues in care of children among nurses shows that the posttest mean score of knowledge was 21.83 with standard deviation 1.97 and the post-test mean score of practice was 12.73 with standard deviation 1.35. The calculated Karl Pearson's Correlation value ' $r$ ' $=0.856$ shows high positive correlation between post-test knowledge and practice scores which was found to be statistically highly significant at $\mathrm{p}<0.001$ level. This clearly infers that knowledge regarding legal and ethical issues in care of children among nurses increases their practice level also increases

\section{SECTION E: Association of level of knowledge and practice with selected demographic variables}

It was seen that the demographic variable age had shown statistically significant association with pre-test level of knowledge regarding legal and ethical issues in care of children among nurses $p<0.01$ level and other demographic variables had not shown statistically significant association with pre-test level of knowledge regarding legal and ethical issues in care of children among nurses. And in post-test it shows that the demographic variable age had shown statistically significant association with post-test level of practice regarding legal and ethical issues in care of children among nurses $\mathrm{p}<0.05$ level and other demographic variables had not shown statistically significant association with post-test level of practice regarding legal and ethical issues in care of children among nurses.

\section{Conclusion}

Hence, the planned teaching programme was instructionally effective, appropriate and feasible. It would help the nurses to prevent legal and ethical issues in care of the children.

\section{Declarations}

\section{Source of Funding}

This research did not receive any grant from funding agencies in the public, commercial, or not-for-profit sectors.

\section{Competing Interests Statement}

The authors declare no competing financial, professional and personal interests.

\section{Ethical Approval}

Ethical approval was given based on the institutional guidelines.

\section{Consent for publication}

Authors declare that they consented for the publication of this research work.

\section{Availability of data and material}

The data collection was done with prior permission from the Principal, Saveetha College of Nursing, SIMATS, Thandalam, Chennai, Tamilnadu, India., and ethical clearance was obtained from the same institution. Authors are willing to share data and material according to the relevant needs. 


\section{References}

1. Marlow D.R., Redding B.A, Textbook of Pediatric Nursing, $6^{\text {th }}$ ed, Pennsylvania: Elsevier Private Limited, 2007.

2. Nursing Ethics, The free dictionary by Farlex, [cited 2017 April 3].

Available from: http://medical-dictionary.thefreedictionary.com/nursing+ethics.

3. R. Srinivasan, Health care in India-vision 2020, [Online], [2004] [cited 2011 Nov 20].

Available from: http://www.planningcommission.nic.in/report/genrep/bkpap2020/26_bg2020.doc.

4. Legal Issues-in-Nursing-Practice, Available from slideshare.net, viewed 22 March 2016.

5. Edward, Taunda. Legal aspects in nursing, [online], 2010 [cited 2011 Nov 08].

Available from: http://www.ehow. com/ 5192939_ legal-issues-nursing.html.

6. International Journal of Medicine and Biomedical Research 5(2): 67-76, June 2016.

Available from: https:// www.researchgate/publication/305272186.

7. American Journal of Diseases of Children, [serial online] 1988, [cited 2011 Nov 08], (142).

Available from: http://archpedi.ama.

8. Dutta Parul, Pediatric Nursing. 2nd ed, New Delhi: Jaypee Publication, 2009, p.1-2. Journal of prosthetics and orthotics, Rajeev Gandhi University of Health Science, Bangalore, Karnataka.

Available from: http//www.medianet.com.

9. Devi WA., (2017), Nurse's awareness on legal and ethical responsibilities in nursing, International Journal of Nursing Research and Practice, 4(1): 53-57.

10. Parul Dutta, Textbook of Pediatric Nursing, I $^{\text {st }}$ edition, Jaypee Brothers, Publications, New Delhi, 2009. 